\title{
Converged wireline and wireless signal transport over optical fibre access links
}

Tafur Monroy, Idelfonso; Prince, Kamau; Osadchiy, Alexey Vladimirovich; Guerrero Gonzalez, Neil; Caballero Jambrina, Antonio; Zibar, Darko; Gibbon, Timothy Braidwood; Yu, Xianbin; Jensen, Jesper Bevensee

Published in:

Proceedings, OECC

Link to article, DOI:

10.1109/OECC.2009.5213923

Publication date:

2009

Document Version

Publisher's PDF, also known as Version of record

Link back to DTU Orbit

Citation (APA):

Tafur Monroy, I., Prince, K., Osadchiy, A. V., Guerrero Gonzalez, N., Caballero Jambrina, A., Zibar, D., Gibbon, T. B., Yu, X., \& Jensen, J. B. (2009). Converged wireline and wireless signal transport over optical fibre access links. In Proceedings, OECC (pp. 1-2). IEEE. https://doi.org/10.1109/OECC.2009.5213923

\section{General rights}

Copyright and moral rights for the publications made accessible in the public portal are retained by the authors and/or other copyright owners and it is a condition of accessing publications that users recognise and abide by the legal requirements associated with these rights.

- Users may download and print one copy of any publication from the public portal for the purpose of private study or research.

- You may not further distribute the material or use it for any profit-making activity or commercial gain

- You may freely distribute the URL identifying the publication in the public portal 


\title{
Converged wireline and wireless signal transport over optical fibre access links
}

\author{
Idelfonso Tafur Monroy, Kamau Prince, Alexey Osadchiy, Neil Guerrero González, Antonio Caballero, Darko Zibar, \\ Tim Gibbon, Xianbin Yu, Jesper Bevensee Jensen \\ DTU Fotonik, Technical University of Denmark, DK-2800 Kgs. Lyngby, Denmark \\ Email:idtm@fotonik.dtu.dk
}

\begin{abstract}
This article reviews emerging trends in converged optical-wireless communication systems and outline the role that photonic technologies are playing in making the vision of a wireline-wireless converged signal transport network a reality.
\end{abstract}

\section{Introduction}

Users of tele-information services are demanding instant access, everywhere and anytime. Wireless communication systems offers mobility and flexibility while optical fiber based systems offer large bandwidth, secure and lower power consumption for transport of telecommunication signals. None of the two technologies separately can satisfy the demands of user for ubiquitous and affordable access to information services. Converged optical and wireless systems offer a solution that combines the best of both technologies.

\section{Radio-over-fiber systems}

Current implementations of fiber-to-the-home (FTTH) networks are providing commonly $100 \mathrm{Mb} / \mathrm{s}$ symmetric connectivity at the present time[1]. Recent efforts have also been made to integrate support for converged fixed and wireless access over the same infrastructure, to maximize the utilization of the optical infrastructure [14].Converged access solutions have been a major driver in the development of microwave photonics and radioover-fiber (RoF) systems[1], which seeks to integrate fixed and wireless signal transport over a common optical infrastructure. However, as noted in [1-4] there is alsoRoF technology to support wireless network bridges for link protection or extension. Potential candidate scenarios are presented in Figure 1; we highlight the disaster recovery option shown in Fig. 1a in which immediate network services may be deployed following a disaster event affecting the optical infrastructure. Figure $1 \mathrm{~b}$ shows a potential 'broadband last-mile application, in which network access is provided to a remote community which may be separated from a metropolitan hub so that it is impractical to extend optical transmission lines to provide direct service. In such a scenario, a wireless transmission link may be used to provide connectivity between a remote optical line termination (OLT) equipment and the central office: network connectivity could then be provisioned between end users and the remote OLT via optical infrastructure.

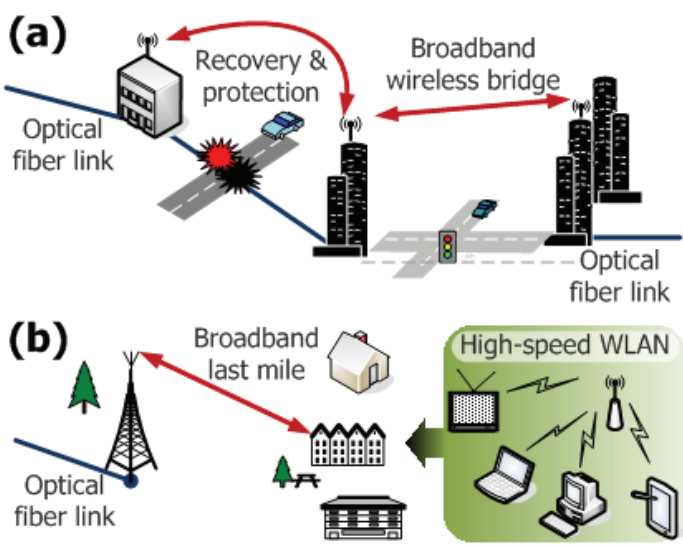

Fig. 1. Scenarios for Radio over Fiber Wireless Bridge for (a) disaster recovery/link protection or (b) broadband last mile.

\section{Impulse radio-UWB over fibre}

The prospects of ultra-wideband (UWB) technology to support high bit-rates, makes it promising to meet the increasing demand from end-users for wireless and persona area communications. However, the stringent specifications of low energy emission and very low signal-to-noise ratio (SNR) under the Federal Communications Commission (FCC) in 2002 [5] and European Electronic Communications Commission (ECC) in 2005 [6] limit it in a short range indoor wireless application (up to $10 \mathrm{~m}$ ). On the other hand, optical fiber-based access technology is commonly considered as a preferential candidate in term of extending the reach distance and providing high transmission capacity. Therefore, UWB-over-fiber technology provides a good solution to transport services to end-users in the case of coexistence with other wireline communication systems. As shown in Fig.2, UWB signals are generated in central office $(\mathrm{CO})$ and delivered for end-users through an existed optical network. In this case, key issues are how to optically generate UWB signals in a simple way at the $\mathrm{CO}$ and to demodulate the impulse based signals at the receiver side. A promising approach is to use distributed feedback laser (DFB) for UWB pulse generation. Schemes using either direct current modulation or external optical modulation of DFB sources have shown prospect for IR-UWB generation capabilities up to $1 \mathrm{Gbit} / \mathrm{s}[7]$ with easy integration into optical fibre access links. 


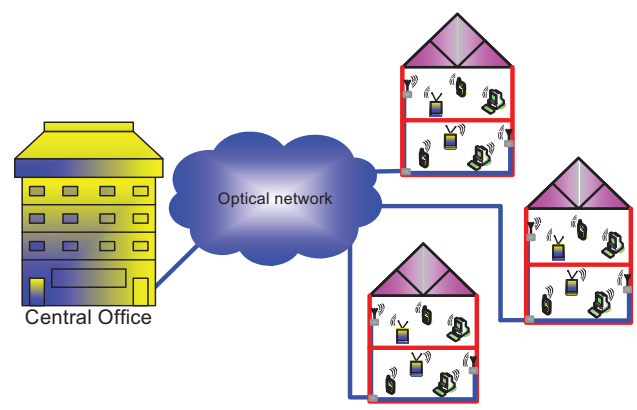

Fig. 2. UWB-over-Fiber technology for short range indoor wireless services.

\section{Coherent detection based optical access networks}

Figure 3a) shows a schematic diagram for a converged wireless-optical network. The same fiber infrastructure is envisaged to transport signal destined to wireline and wireless access points. Radio-over-fiber systems find a natural application in the later scenario. Coherent optical communication is witnessing a revival and radio-overfiber systems employing coherent detection are under investigation [8]. As the use of advanced digital signal processing for optical receiver is opening the way for universal optical digital receivers [9], it is interesting to consider optical access networks exploiting the advantageous features of optical coherent detection. The basic principle of a coherent detection receiver is shown in Fig. 3: The incoming optical signal is mixed with the light from a local oscillator laser (LO) in an optical $90^{\circ}$ hybrid combiner, after photodetection, Inphase and Quadrature component signals are obtained. These electrical signals are then processed by the digital signal processor (DSP) for synchronization, clock-recovery, demodulation and potentially signal degradation compensation. In a coherent detection setup as shown in Fig. 3, the receiver sensitivity is enhanced up to $5-10 \mathrm{~dB}$ $[9,10]$ compared to a direct detection scheme depending on the used modulation format. Such an increase in the receiver sensitivity can be used to compensate for losses in power splitters and brings coherent system close in terms of power budget to wavelength division multiplexing (WDM) passive optical networks (PONs) as the number of users is increased. Moreover, by using a wavelength tunable LO, any channels in the network can be selected which means great flexibility for example to implement broadcast services. As only the targeted channel is down-converted to baseband during coherent detection, selective electrical filtering allows for high spectral efficiency.

\section{Conclusions}

Hybrid optical-wireless networks are foreseen to play an important role in securing a telecommunication infrastructure able to delivery wireless and wireline services to the end-user in an efficient, reliable and affordable cost per unit of bandwidths. Photonic a)
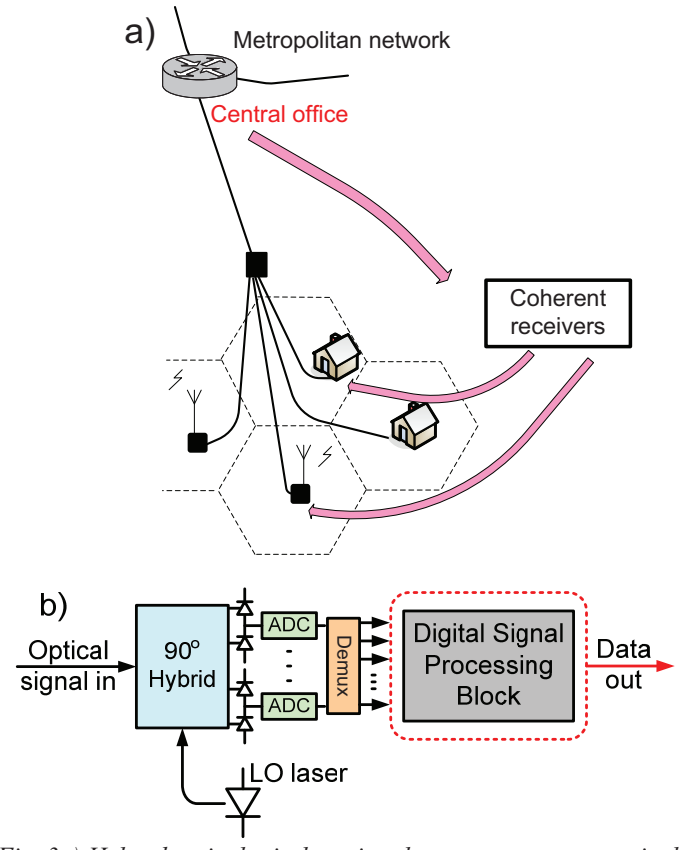

Fig. 3a) Hybryd optical-wireless signal transport over an optical access networks supported by coherent detection recivers. b) Schematic diagram of a coherent receiver supported by DSP techniques, where LO laser is the local oscillator source, ADCanalogous-digital converters, and Demux is a parallelizing demultiplexer.

technologies such as radio-over-fiber, photonic generation and transport of IR-UWB signals and advanced coherent detection receivers supported by DSP technology are identified as key approached to realize the potential and prospects of a hybrid optical-wireless converged access networks.

\section{References}

1. Capmany, J. \& Novak, D. Microwave photonics combines two worlds Nature Photon., 2007, 1, 319-330

2. Seoane et al., Local-Oscillator-Free Wireless-Optical-Wireless Data Link at 1.25 Gbit/s over a $40 \mathrm{GHz}$ Carrier Employing Carrier Preservation and Envelope Detection. Proc OFC. 2008, OThD4

3. Shinohara, H. FTTH experiences in Japan. J. Opt. Netw., , 6, 616623, 2007

4. Prince, K. \& Tafur Monroy, I. All-Optical Envelope Detection and Fiber Transmission of Wireless Signals by External Injection of a DFB Laser IEEE Photonics Technol Lett, 2008, 20, 1317-1319

5. X. Gu and L. Taylor, "Ultra-wideband and its capabilities," BT Technology Journal, vol.21, no.3, pp.56-66, July 2003.

6. "An input document for discussion at ECC TG3-11 CEPT/EU," (2005) and FCC UWB regulation documents.

7. T. B. Gibbon, Xianbin Yu, D. Zibar, I. T. Monroy, "Novel ultrawideband photonic signal generation and transmission featuring digital signal processing bit error rate measurements", OFC/NFOEC2009, March 2009, California, USA, Paper: OTuB8

8. D. Zibar, X. Yu, C. Peucheret, P. Jeppesen, and I. T. Monroy. "Digital Coherent Receiver for Phase-Modulated Radio-Over-Fiber Optical Links", IEEE Photonic Technology Letters, vol. 21, no.. 3 , 155-157, 2009

9. E. Ip, A. P. Tao Lau, D. J. F. Barros, J. M. Kahn, "Coherent detection in optical fiber systems," in Optics Express, vol. 16, no. 2, pp. 753-791, 2008

10. T. Okoshi, K. Kikuchi, "Coherent Optical Fiber Communications," Springer, 1988 